\title{
Systematic differences between ultrasound and pathological evaluation of thyroid nodules: a method comparison study
}

Carolyn R Chew ${ }^{*}$ MBBS, Tracey Lam* FRACS, Steven T. F. Chan ${ }^{\dagger}$ PhD, FRACS, Laura Chin-Lenn * FRACS

* Endocrine Surgery Unit, Department of Surgery, Western Hospital, Melbourne, Victoria, Australia

${ }^{\dagger}$ Department of Surgery, North West Academic Centre, The University of Melbourne, Victoria, Australia

\section{Correspondence}

Dr Laura Chin-Lenn, Endocrine Surgery Unit, Department of Surgery, Western Health.

40 Gordon St Footscray, Melbourne VIC 3011, Australia

Email: laura.chin-lenn@mh.org.au

$\mathrm{Ph}+61383456666$

Fax +61383456885

Reprints will not be available from the author(s).

\section{Original Article}

Key words pathology, ultrasound, thyroid, nodules

Short title: Size Discrepancy of Thyroid Nodules

Conflict of interest: None declared

Abstract Word Count: 250

This is the author manuscript accepted for publication and has undergone full peer review but has not been through the copyediting, typesetting, pagination and proofreading process, which may lead to differences between this version and the Version of Record. Please cite this article as doi: 10.1111/ans.14045

This article is protected by copyright. All rights reserved. 
Manuscript Word Count: 2539

Figures 3 Tables 3

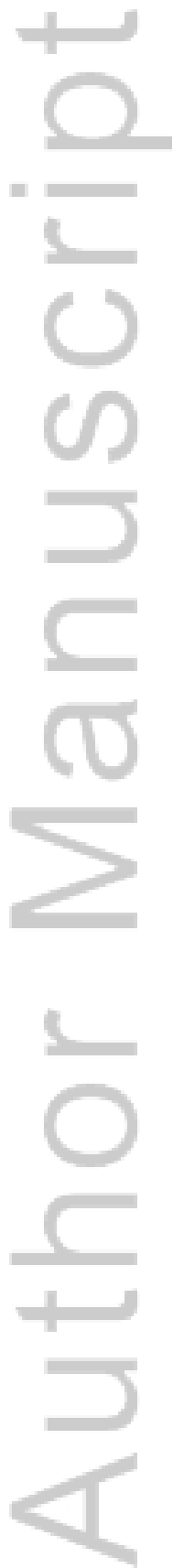

This article is protected by copyright. All rights reserved. 


\section{Abstract}

Background: The size of thyroid nodules as measured by ultrasound (USS) is routinely used in clinical decision-making. Reports of size discrepancy between USS and pathological (PS) evaluation have not analysed their systematic differences. The objective of this study was to uncover lack of agreement (bias) between USS and PS measurements.

Methods: A retrospective study was performed on 121 patients who had a total or hemithyroidectomy for a solitary nodule. Ordinary Least Product (OLP) regression was used to detect and distinguish constant and proportional bias in unidimensional size measurements between USS and PS evaluation. Three-dimensional volume measurements were compared in a subgroup of 31 patients. Pre-specified acceptable limits of interchange were defined as $20 \%$ difference.

Results: OLP regression demonstrated no constant or proportional bias between the two methods; regression equation: USS $=(0.863)+(1.040) * \mathrm{PS}$. When nodules were grouped by size, discrepancies between the two methods were observed in nodules less than $10 \mathrm{~mm}(\mathrm{p}=$ 0.004). However, potential over-treatment of patients with ultrasound size $>10 \mathrm{~mm}$ but pathological size $<10 \mathrm{~mm}$ only accounted for $4.1 \%$ of total patients. Subgroup analysis of volume measurements showed no bias between USS and PS evaluation.

This article is protected by copyright. All rights reserved. 
Conclusions: USS and PS measurements were interchangeable, as there was no evidence of constant or proportional bias between the two measurements. However, USS may misclassify the size for smaller nodules and potentially lead to unnecessary workup and treatment. Discrepancy in size measurements between USS and PS should be taken into account in clinical practice, particularly in smaller nodules.

\section{Introduction}

High-resolution ultrasound is recommended for all patients with known or suspected thyroid nodules ${ }^{1}$. This assesses the risk of malignancy by evaluating nodule size, number, parenchymal characteristics such as echogenicity, calcifications, internal vascularity, margins and the presence of associated cervical lymphadenopathy ${ }^{1,2}$. Furthermore, ultrasound measured nodule size (USS) plays a critical role in selecting patients for further evaluation with fine needle aspiration (FNA) and surgical decision making.

Current American Thyroid Association (ATA) guidelines give strong recommendations for routine FNA in nodules $>10 \mathrm{~mm}$ if classed as high or intermediate risk on imaging. Fine needle aspiration of lesions $>15 \mathrm{~mm}$ is recommended for nodules with low risk features on imaging (weak recommendation, based on low quality evidence). In solitary nodules between 1-4cm (on US) without extra-thyroidal extension or evidence of lymph node metastases, patients may undergo either lobectomy or total thyroidectomy, depending on patient preference, pre-operative pathology and need for radioactive iodine treatment. 
However, it is the histopathological size (PS) in malignant nodules that determines the final TNM classification ${ }^{1}$.

There are limited data comparing USS and PS, and these studies have not analysed their systematic differences ${ }^{3-5}$. The primary objective of this study was to uncover the lack of agreement (bias) between USS and PS measurements using a method comparison study. The secondary aim was to assess nodules with USS $<10 \mathrm{~mm}$, as size discrepancies may alter management decisions.

\section{Materials and Methods}

A retrospective study was undertaken to examine patients who underwent total or hemi-thyroidectomy at our institution for a solitary thyroid nodule between January 2009 and October 2015. Patient demographics, thyroid function, USS, FNA cytology, histopathological diagnosis and PS were recorded. Patients with multiple nodules were excluded from the study to prevent discrepancies due to sonographers and pathologists measuring different nodules in the same specimen.

Pre-operative ultrasounds were performed at our institution and multiple external radiology providers. All ultrasounds were reported by consultant radiologists, and measurements were taken prior to FNA. PS was measured in our pathology department following formalin fixation and cross section by the pathologist. We used the largest recorded USS and PS measurements in 121 patients for unidimensional size comparison. In 31 patients, three-dimensional volume measurements were available for subgroup analysis. The unit of 
measurement for USS and PS size and volume is in millimetres ( $\mathrm{mm})$ unless otherwise stated. The study was approved by the Western Health Ethics committee.

\section{Statistical Analysis}

A scatterplot of ultrasound measurements (USS) on pathology measurements (PS) was constructed and Pearson's product-moment correlation coefficient and the coefficient of determination calculated. No assumption was made that USS or PS measurements were errorfree $^{6-9}$. Ordinary Least Product (OLP) regression was used to uncover systematic differences and, in particular, to detect and distinguish constant (fixed) and proportional bias between the two measurements (method-comparison study) ${ }^{10,11}$. Constant bias is where one method gives values that are higher (or lower) by a constant amount. Proportional bias is where one method gives values that are higher (or lower) by an amount that is proportional to the level of the measured variable. Assumptions for using OLP regression including linearity and equality of variances in the scatterplot were tested. Subgroup analysis of volume comparison was made where three-dimensional measurements were available. Non-parametric exact (permutation) test for two related samples were used to compare nodules grouped by size. Pre-specified acceptable limits of interchangeable results were defined as 20 per cent.

Continuous data are presented as median (IQR, inter-quartile range). All tests were two-sided, and $p<0.050$ was considered significant. Statistical analyses were performed using Systat v12 (Systat Software, Inc, Chicago, IL, USA) for OLP regression and StatXact v9.0 (Cytel Software Corporation, Cambridge MA, USA) for categorical data with exact nonparametric methods. 


\section{Results}

There were 121 eligible patients and demographics are summarised in Table 1 . The median age of patients was 47 , with a female predominance $(66 \%)$ and the majority of patients were euthyroid (82\%). The median USS was $27 \mathrm{~mm}$ (IQR $15-39 \mathrm{~mm}$ ) and the median PS was 25mm (IQR13-35mm).

\section{Method Comparison Analysis}

A scatterplot of USS and PS measurements is shown in Fig. 1. The correlation coefficient $(r)=0.888 ; 95 \%$ confidence interval $(\mathrm{CI}): 0.844$ to $0.921 ; \mathrm{p}<0.001$; and the coefficient of determination $\left(\mathrm{r}^{2}\right)=0.789$, which implied that $80 \%$ of the variation in USS measurements was accounted for by knowing the PS measurements and vice versa.

The variance (or scatter) of USS was constant across all values of PS, an essential assumption for using OLP regression (homoskedastic distribution: $C^{2} 2.43, \mathrm{~d} f 2, \mathrm{p}=0.296$ ). Fig. 2 shows the residual plot of the regression model, the residual is the difference between the observed and predicted value of the USS measurements. The random pattern of the residuals around the horizontal axis supported a linear model.

The results of OLP regression for unidimensional size and volume comparisons are shown in Table 2. The 95\% CI for the intercept (-1.831 to 3.557) included a zero (0) value implied no constant bias; the $95 \%$ CI for the slope (0.951 to 1.129 ) included a one (1) value implied no proportional bias. The regression equation for the model is:

$$
\mathrm{USS}=0.863+1.040 * \mathrm{PS}
$$


No constant or proportional bias was uncovered between USS and PS evaluation in the subgroup analysis for volume measurements.

\section{Analysis of nodules grouped by size}

Analysis based on PS is illustrated in Fig 3 and Table 3. There was no significant difference between USS and PS for nodules measuring $11-15 \mathrm{~mm}$ and nodules $>15 \mathrm{~mm}$. For nodules $<10 \mathrm{~mm}$ there was a significant difference $(\mathrm{p}=0.004)$ between US and PS measurements.

Thirteen patients had nodules with USS less than $10 \mathrm{~mm}$. Within this group, 8/11 nodules that had FNA were suspicious for, or malignant on cytology. Only one nodule was underestimated with PS $11 \mathrm{~mm}$. Nineteen patients had nodules with PS less than or equal to $10 \mathrm{~mm}$ and the USS ranged from $5-20 \mathrm{~mm}$. There was a statistically significant difference on exact permutation test ( $\mathrm{p}$ value 0.004 , median PS $9 \mathrm{~mm}$ vs. USS $10 \mathrm{~mm}$ ). Sixteen patients had an FNA and ten were suspicious for, or confirmed malignancy. Seven were over-estimated with USS $>10 \mathrm{~mm}$. As a percentage of the total patients with USS measuring between 10-20 $\mathrm{mm}(\mathrm{n}=45)$ this only represented $16 \%(7 / 45)$ of nodules that may have been over-treated.

\section{Discussion}

The principal finding of this study was that ultrasound measurements were interchangeable with pathological measurements. Analyses of measurements showed no evidence of constant or proportional bias. Published studies comparing USS with PS have not analysed the systematic differences between measurement methods ${ }^{3-5}$. However, similar to our study, all of these studies demonstrated a tendency for USS to over-estimate PS. 
In a study of 292 patients with papillary thyroid carcinoma' by Bachar et al, consistent size discrepancy was noted, although it was only statistically significant in nodules measuring more than $15 \mathrm{~mm}$. They also found that $18.8 \%$ of nodules measured to be $>10 \mathrm{~mm}$ on USS were $<10 \mathrm{~mm}$ on final pathology, suggesting that some patients may have potentially been over-treated ${ }^{4}$. Devici et al $^{5}$ compared USS and PS on 664 benign and malignant solitary nodules. Nodules were stratified based on size criteria. This study demonstrated an overall concordance between USS and PS of $<50 \%$, except for nodules $<10 \mathrm{~mm}$ where there was a concordance of $78.5 \%$. A study by Sowerby et $\mathrm{al}^{3}$ in 2011 evaluated 263 patients with solitary thyroid nodules. They demonstrated a median overestimation by ultrasound of $5.4 \mathrm{~mm}$ compared with pathological size. This was consistent with subgroup analysis for size, pathology and nodularity. For nodules $<10 \mathrm{~mm}$, a concordance of $80 \%$ was present.

The current ATA guidelines recommend FNA for patients with USS $>10 \mathrm{~mm}$ with intermediate to high suspicion features on US, and routine FNA for patients with USS $>15$ $\mathrm{mm}^{1}$. In our study, we demonstrated a statistically significant difference between PS and USS for nodules d10mm. Seven (4.1\%) patients with PS less than $10 \mathrm{~mm}$ had an USS $>10 \mathrm{~mm}$. This may represent some patients who have potentially been over-treated with FNA and choice of surgery. However, we examined ultrasound size alone, and did not take into account the other nodule characteristics on US or risk factors that may have prompted FNA. There are many important features of thyroid nodules on imaging which are important in addition to size, such as echogenicity, irregularity of borders, shape and patterns in calcification and vascularity. A large proportion (61.5\%) of the patients with USS $<10 \mathrm{~mm}$ had either suspected or confirmed malignancy on pre-operative FNA, which was confirmed on final 
pathology in $100 \%$ of cases. However, for nodules with USS less than over equal to $10 \mathrm{~mm}$, PS was close to the same size, and management would not have been altered.

There are many possible factors to account for the discrepancy between USS and PS, and it is likely multi-factorial. High-resolution ultrasound is the "gold standard" for assessment of thyroid nodules, for its reliability, cost-effectiveness, accessibility and noninvasive nature. However, limitations include being operator-dependent with an interobserver variation of up to $48.96 \%$ for estimated thyroid volume ${ }^{12-15}$, and its accuracy influenced by poorly defined nodule margins, irregular shapes, multi-nodular goitre and large nodules ${ }^{16}$

A number of factors contribute to PS discrepancy. There may be more than 50\% volume increase on serial US following thyroid nodule FNA in up to $35 \%$ of patients, possibly due to post aspiration scarring or haemorrhage ${ }^{17}$. De-vascularisation of the gland following removal has been postulated to contribute to size discrepancy and nodule shrinkage ${ }^{16}$. Shrinkage of specimens following formalin fixation is a phenomenon that has been described in a number of different specimens. A study examining 100 head and neck specimens, including 16 thyroid specimens demonstrated an average shrinkage of maximal diameter of $4.40 \%{ }^{18}$. The measured nodule size also depends on the plane in which the nodule has been sectioned by the pathologist, and the plane examined by US, particularly as most nodules are not perfectly spherical.

The main limitation of this study was its retrospective nature. Duplicate measurements were not made and assessment of repeatability not available. It is important that nodule 
assessment on US is performed and interpreted by experienced endocrine radiologists. Whilst some of the imaging in our study was performed at our institution, a majority of the US were performed at external provider sites. This raises the issue of inter-observer variation.

However, our study is reflective of 'real world experience' where external US results are used in patient assessment and decision-making.

\section{Conclusion}

We demonstrated that USS and PS measurements were interchangeable. Analyses of measurements showed no evidence of constant or proportional bias between the two measurements. Potential over-treatment of patients with ultrasound size greater than $10 \mathrm{~mm}$ and pathological size less than $10 \mathrm{~mm}$ only accounted for $4.1 \%$ of patients. USS may misclassify the size for the smaller nodules and potentially lead to unnecessary workup and treatment. The decision for investigation and treatment of thyroid nodules is based on a number of factors not solely the USS. However, discrepancy in size measurements between USS and PS should be taken into account in clinical practice.

This article is protected by copyright. All rights reserved. 


\section{References}

1. Haugen BR, Alexander EK, Bible KC et al. American thyroid association management guidelines for adult patients with thyroid nodules and differentiated thyroid cancer. Thyroid 2016; 26: 1-133. DOI: 10.1089/thy.2015.0020.

2. Kang HW, No JH, Chung JH et al. Prevalence, clinical and ultrasonographic characteristics of thyroid incidentalomas. Thyroid 2004; 14: 29-33.

3. Sowerby L, Franklin JH, Chin CJ et al. Discrepancy between Ultrasound and Final Pathological Measurements in Thyroid Cancer. J Otolaryngol Head Neck Surg 2011; 40: $453-7$.

4. Bachar G, Buda I, Cohen M et al. Size discrepancy between sonographic and pathological evaluation of solitary papillary thyroid carcinoma. Eur J Radiol 2013; 82: 1899-903.

5. Devici MS, Deveci G, LiVolsi VA et al. Concordance between thyroid nodule sizes measured by ultrasound and gross pathology examination: effect on patient management. Diagn Cytopath 2007; 35: 579-82.

6. Ludbrook J. Comparing methods of measurement. Clin Exp Pharmacol Physiol 1997; 24: 193-203.

7. Batterham AM. Commentary on bias in Bland-Altman but not regression validity analyses. Sportscience 2004; 8: 47-9.

8. Bland JM, Altman DG. Statistical methods for assessing agreement between two methods of clinical measurement. Lancet 1986; 1: 307-10. 
9. Ludbrook J. Confidence in Altman-Bland plots: a critical review of the method of differences. Clin Exp Pharmacol Physiol 2010; 37:143-9.

10. Ludbrook J. Linear regression analysis for comparing two measurers or methods of measurement: but which regression? Clin Exp Pharmacol Physiol 2010; 37: 692-9.

11. Ludbrook J. A primer for biomedical scientists on how to execute model II regression analysis. Clin Exp Pharmacol Physiol 2012; 39: 329-35.

12. Hegedus L, Perrild H, Poulsen LR et al. The determination of thyroid volume by ultrasound and and its relationship to body weight, age and sex in normal subjects. $J$ clin Endocrinol Metab 1983; 56: 260-3.

13. Knudsen N, Bols B, Bulow I et al. Validation of ultrasonography of the thyroid gland for epidemiological purposes. Thyroid 1999; 9:1069-74

14. Brauer VF, Eder P, Miehle K et al. Interobserver variation for ultrasound determination of thyroid nodule volumes. Thyroid 2005; 15: 1169-75.

15. Choi SH, Kim EK, Kwak JY et al. Interobserver and intraobserver variation in ultrasound assessment of thyroid nodules. Thyroid 2010; 20: 167-72.

16. Gordon DL, Flisak M, Fisher SG. Changes in thyroid nodule volume caused by fine needle aspiration: a factor complicating the interpretation of thyrotropin suppression on nodule size. J Clin Endocrinol Metab 1999; 84: 4566-9.

17. Gallo M, Pesenti M and Valcavi R. Ultrasound thyroid nodule measurements: the "gold standard" and its limitations in clinical decision making. Endocr Pract 2004; 9: 194-9.

This article is protected by copyright. All rights reserved. 
18. Chen CH, Hsu MY, Jiang RS et al. Shrinkage of head and neck cancer specimens after formalin fixation. J Chin Med Assoc 2012; 75: 109-13.

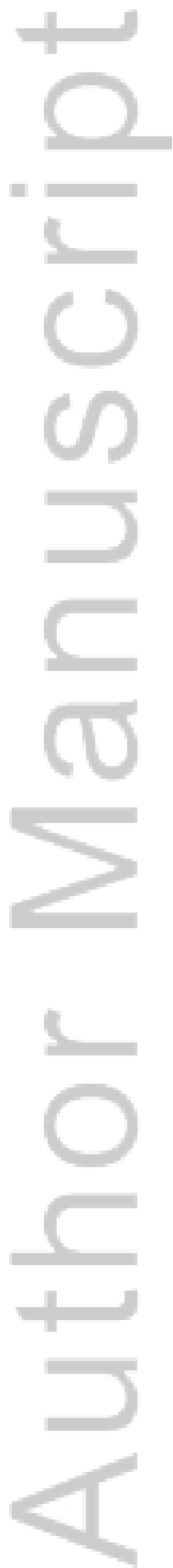

This article is protected by copyright. All rights reserved. 


\section{Legend for Figures}

Fig. 1 Scatter plot of Ultrasound Size versus Pathological Size

Fig. 2 Residual plot of Regression Model

Fig. 3 Analysis of Thyroid Nodules by Pathological Size

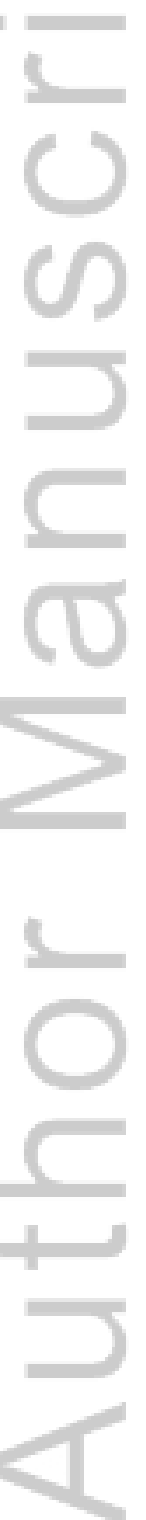

This article is protected by copyright. All rights reserved. 
Table 1 Patient demographics and thyroid status of 121 patients with solitary thyroid nodules

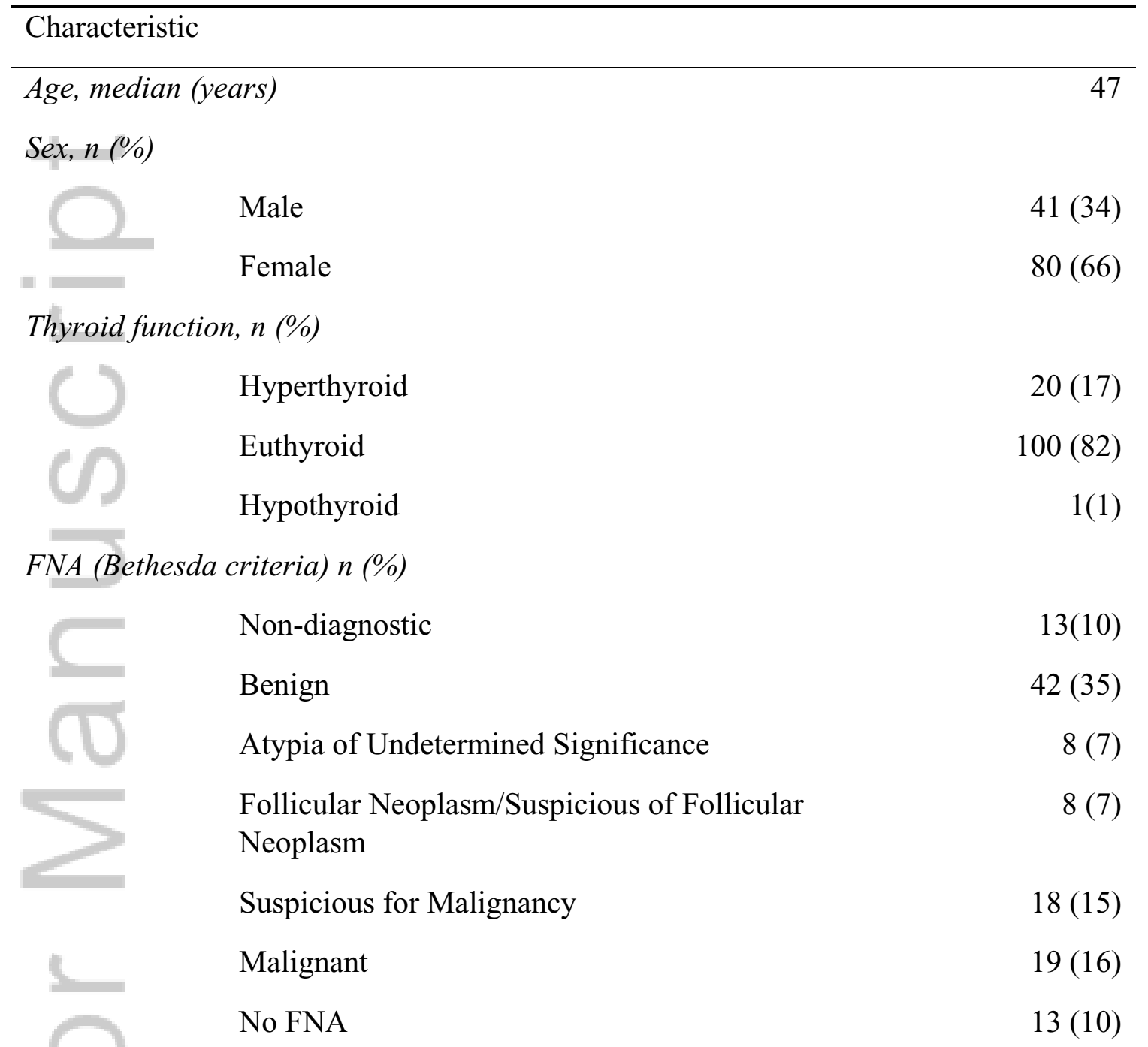

Size, $m$ m, inter-quartile range

USS median

PS median

Final Histopathology, $n(\%)$

Hyperplastic or colloid nodule $26(21)$

Adenoma 35 (29)

$\begin{array}{ll}\text { Cyst } 12(10) & 12\end{array}$

Malignancy 38 (30) 
Table 3 USS and PS grouped by nodule size (mm)

\begin{tabular}{ccccc}
\hline $\begin{array}{c}\text { Group by size } \\
\text { (PS) }\end{array}$ & $\mathrm{n}$ & $\begin{array}{c}\text { USS, } \\
\text { median (IQR) }\end{array}$ & $\begin{array}{c}\text { PS, } \\
\text { median (IQR) }\end{array}$ & p exact \\
\hline $\mathrm{d} 10$ & 19 & $10.00(8.25-16.00)$ & $9.00(7.00-10.00)$ & 0.004 \\
$11-15$ & 20 & $13.00(12.00-17.00)$ & $13.00(12.00-15.00)$ & 0.213 \\
$>15$ & 82 & $33.00(27.00-44.00)$ & $31.00(25.00-41.00)$ & 0.141 \\
\hline
\end{tabular}

This article is protected by copyright. All rights reserved. 


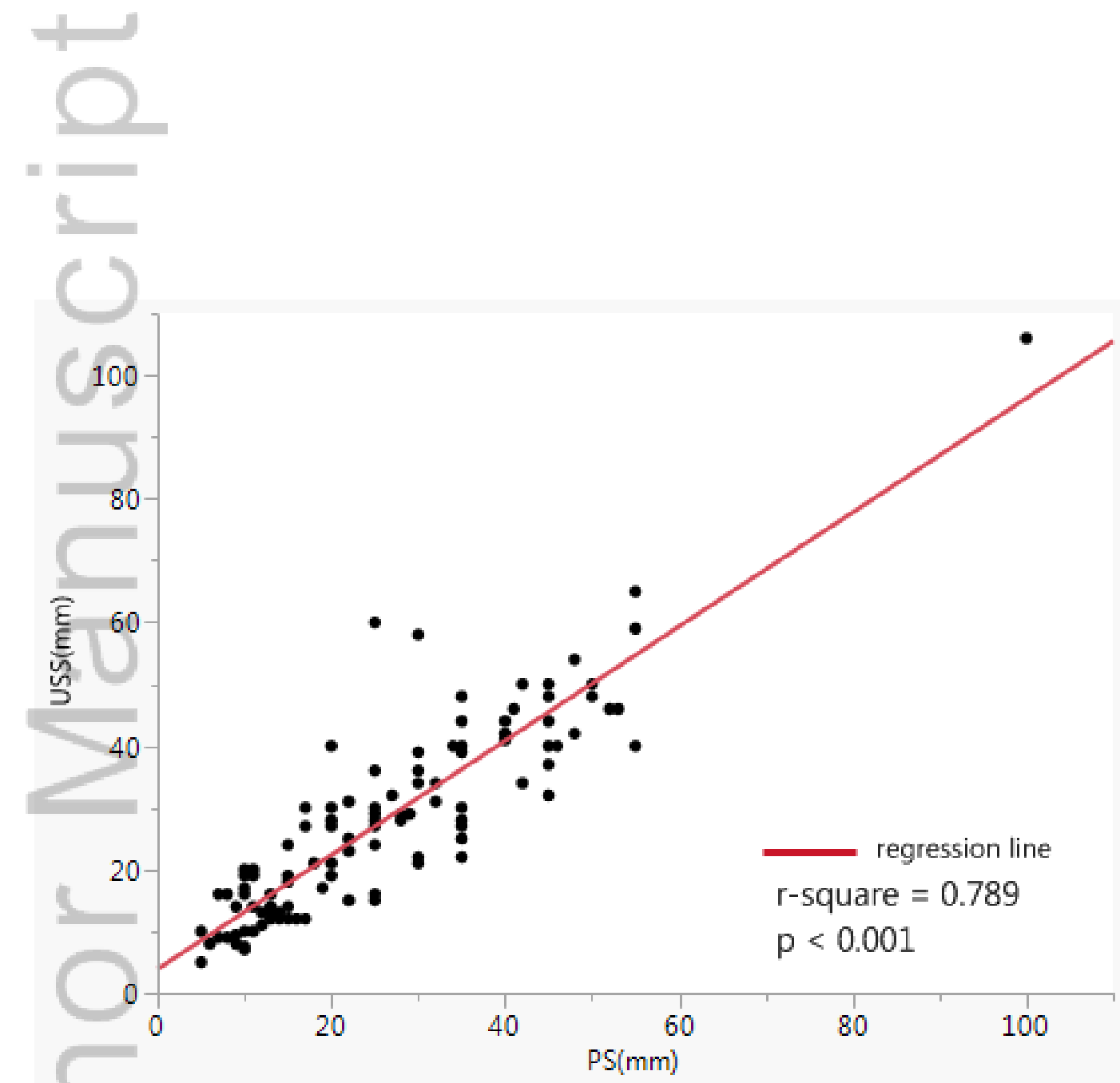

Figure1.tif

This article is protected by copyright. All rights reserved. 


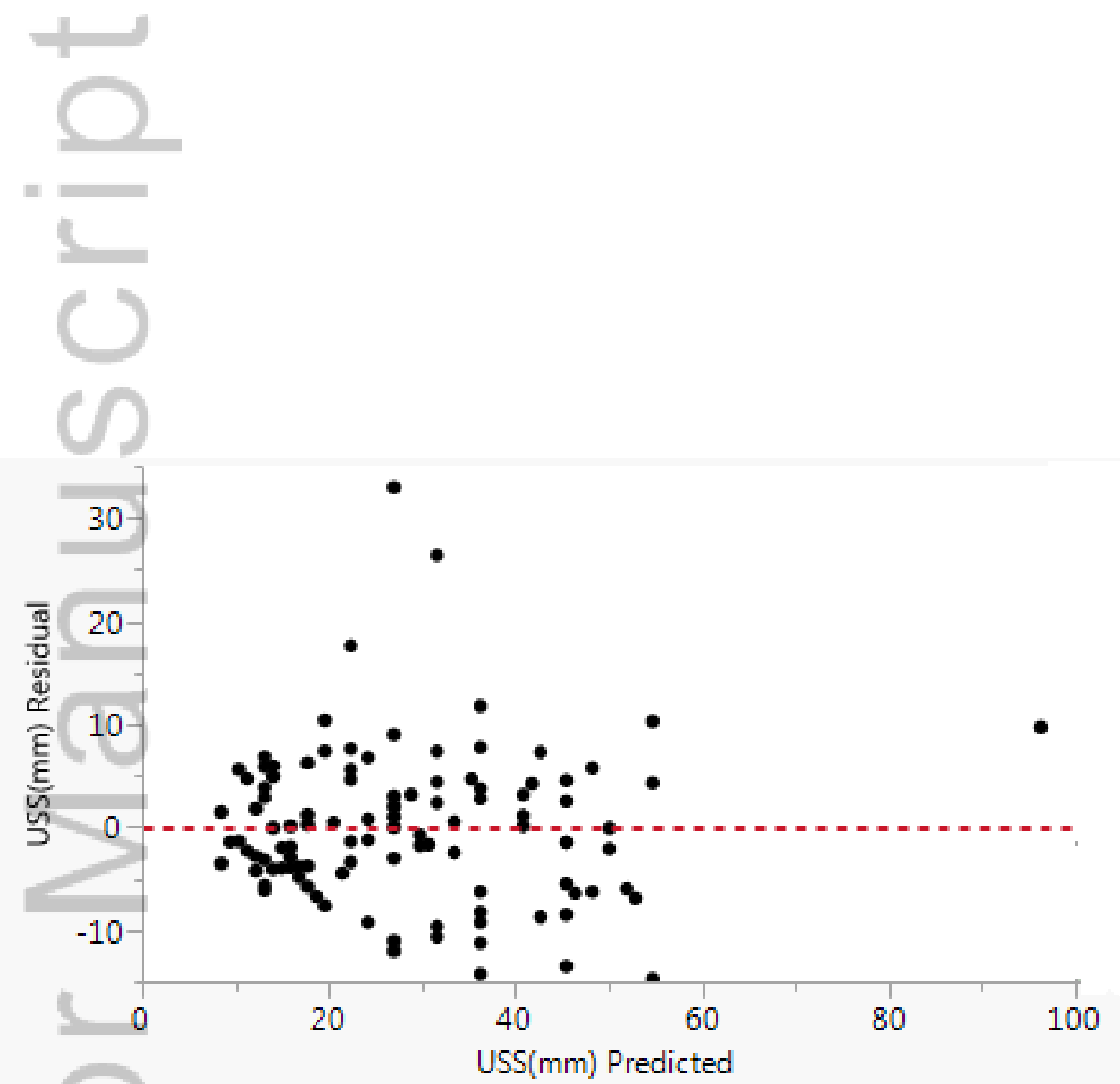

Figure2.tif

This article is protected by copyright. All rights reserved. 


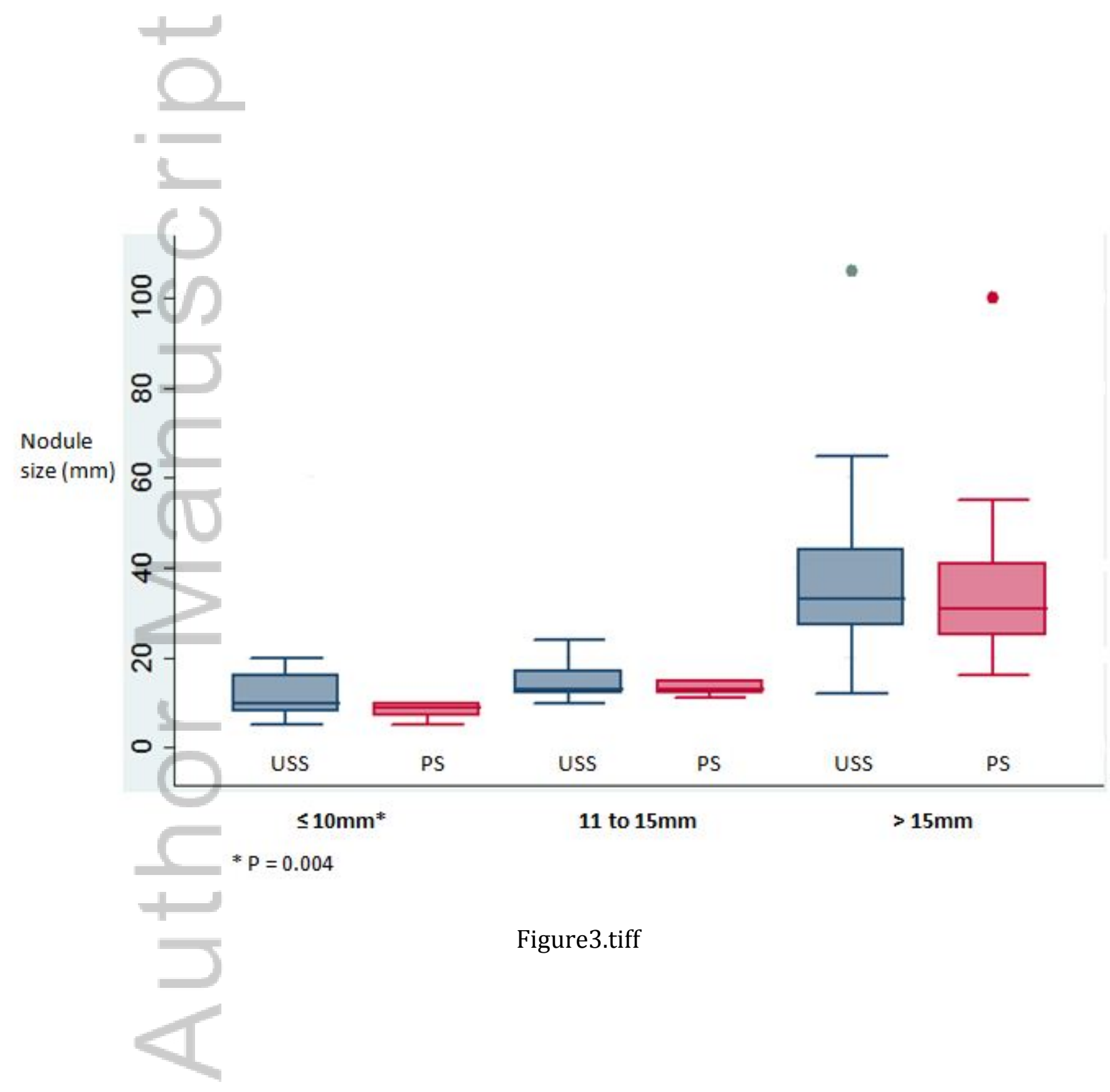

This article is protected by copyright. All rights reserved. 
Table 2 Results of OLP Regression: USS vs PS measurements

\begin{tabular}{ccccc}
\hline Parameter & Estimate & ASE & Paramter/ASE & Wald 95\% CI \\
\hline Intercept $^{\text {I/ }}$ & 0.86 & 1.36 & 0.64 & -1.83 to $3.56^{\dagger}$ \\
Slope & 1.04 & 0.05 & 23.09 & 0.95 to $1.13^{\ddagger}$ \\
\hline Intercept $^{\S}$ & 180.27 & 1889.14 & 0.10 & -3683.45 to $4043.99^{\dagger}$ \\
Slope $^{\S}$ & 0.89 & 0.03 & 27.97 & 0.82 to $1.02^{\ddagger}$ \\
\hline
\end{tabular}

I unidimensional size comparison $n=121, \S$ volume comparison $n=31, \uparrow$ no constant bias, $\ddagger$ no proportional bias, OLP ordinary least product, USS ultrasound size, PS pathological size, ASE asymptotic standard error.

This article is protected by copyright. All rights reserved. 


\section{University Library}

\section{- M M N E R VA A gateway to Melbourne's research publications}

Minerva Access is the Institutional Repository of The University of Melbourne

Author/s:

Chew, CR;Lam, T;Chan, STF;Chin-Lenn, L

Title:

Systematic differences between ultrasound and pathological evaluation of thyroid nodules: a method comparison study

Date:

2018-05-01

Citation:

Chew, C. R., Lam, T., Chan, S. T. F. \& Chin-Lenn, L. (2018). Systematic differences between ultrasound and pathological evaluation of thyroid nodules: a method comparison study. ANZ JOURNAL OF SURGERY, 88 (5), pp.464-467. https://doi.org/10.1111/ans.14045.

Persistent Link:

http://hdl.handle.net/11343/293022 